\title{
GESTÃO ESTRATÉGICA DE CIDADES: CONSTRUINDO CONSENSO E COMPROMISSO ATRAVÉS DE UM MODELO DE APOIO A DECISÃO
}

\section{CITIES' STRATEGIC MANAGEMENT: BUILDING CONSENSUS AND COMMITMENT BY A DECISION AID MODEL}

\author{
Felipe Reis Graeml ${ }^{1}$; Rolf Hermann Erdmann ${ }^{2}$ \\ ${ }^{1}$ Universidad Europea de Madrid- UEM - Brasil \\ felipe.reis@uem.es \\ ${ }^{2}$ Universidade Federal de Santa Catarina - UFSC - Brasil \\ erdmann@cse.ufsc.br
}

\begin{abstract}
Resumo
O atual cenário político-administrativo brasileiro deixa cada vez mais evidente a necessidade de soluções estratégicas dedicadas aos problemas locais, de cada cidade, estado ou região. Este problema parece ocorrer também em países com diferentes sistemas democráticos, inclusive em países do primeiro mundo. O próprio sistema democrático possibilita - como era de se esperar-a participação de pessoas e coalizões com diferentes pontos de vista e interesses. Este artigo apresenta parte do estudo da tese de doutorado de um dos autores e descreve o arquétipo de um modelo que integra a Investigação Apreciativa à Soft Systems Methodology. A integração destas metodologias resulta em um modelo teórico-metodológico que pode auxiliar a elaboração de estratégias sustentáveis e efetivas, que aumenta a possibilidade de negociação entre as diferentes partes e que pode ser dedicado às necessidades e potencialidades particulares de cada cidade. Como resultado desta integração apresenta-se um modelo de apoio à decisão que facilita o consenso e a união de forças em busca de objetivos comuns, possibilitando a melhoria da qualidade de vida da população local.
\end{abstract}

Palavras-chave: investigação apreciativa; soft systems methodology; planejamento estratégico urbano; consenso decisório, modelo de apoio à decisão.

\section{Introdução}

Este trabalho propõe um arquétipo que integra a Investigação Apreciativa (Appreciative Inquiry - AI) à Soft Systems Methodology (SSM). O modelo teórico-metodológico descrito a seguir resume um estudo desenvolvido na tese de doutorado de um dos autores. Este modelo busca auxiliar aos administradores municipais na elaboração de estratégias efetivas, dedicadas às necessidades e potencialidades de cada cidade. Favoravelmente à proposta pode-se argumentar que os recursos econômicos dos municípios estão cada vez mais escassos e os problemas aumentam em complexidade com o crescimento ou maior tamanho das cidades. Também, como consequente disso ocorre o distanciamento entre a população os políticos e redução da percepção das demandas populares por parte dos políticos e gestores públicos. Os governantes municipais precisam controlar 
gastos e gerar recursos financeiros que possibilitem o desenvolvimento local, sem comprometer recursos destinados por lei a outros fins, o que exige decisões eficazes e efetivas para problemas sociais, econômicos e políticos.

As metodologias rígidas de decisão (hard systems) têm sido amplamente utilizadas nas mais diversas áreas de estudo. Contudo, as estratégias decorrentes da utilização destes modelos têm demonstrado ser pouco eficazes no tratamento de problemas e situações complexas, dinâmicas, desordenadas e confusas, como é o caso do planejamento estratégico de cidades.

A dificuldade de utilização dos modelos construtivistas no apoio à decisão e a ineficiência dos modelos prescritivos não atraem gestores municipais à sua utilização. Como consequência disso, os modelos de administração adotados pelos prefeitos e suas equipes acabam sendo intuitivos ou guiados por práticas corretivas, que acabam comprometendo o desenvolvimento local e a efetividade das estratégias estabelecidas, acarretando em planos e ações sem sustentabilidade à médio e largo prazo. A utilização de um modelo de apoio à decisão que auxilie a construção do conhecimento sobre os problemas e potencialidades locais pode estimular a convergência de forças, políticas e populares, no sentido de explorar as potencialidades da região e possibilitar a elaboração de estratégias de desenvolvimento urbano sustentáveis.

\section{O modelo SSM e o foco nos problemas}

A Soft Systems Methodology (SSM), desenvolvida pelo professor Peter Checkland da Universidade de Lancaster - Inglaterra segue uma linha construtivista, flexível e de visão sistêmica. Segundo Naughton (apud BUNCH, 2000), a SSM estava inicialmente sendo vista como uma metodologia funcional prescritivista, pois propunha uma série de passos que deveriam ser seguidos para se realizar a análise de um sistema. Bunch (2000) diz que apesar dos questionamentos iniciais sobre a metodologia serem heuristicamente úteis, os desenvolvimentos e aplicações mais recentes desta metodologia a tem conduzido para que seja menos prescritiva e mais flexível.

Os fundamentos da SSM defendem a ideia de que soluções de engenharia não são adequadas para o tratamento de situações complexas, confusas, mal definidas e mal estruturadas. Isto se deve em parte, segundo Checkland (1981, p.316), porque este tipo de problema "não pode ser definido como uma pesquisa de meios eficientes para se atingir fins pré-definidos". Checkland diz que os fins, objetivos e proposições podem ser em si só problemáticos e conclui que esta é uma circunstância típica de situações que envolvem atividades humanas. Para Checkland (1981, p.256), o processo de planejamento é muito mais importante que qualquer plano, pois segundo ele "os problemas não permanecem solucionados".

Checkland (1999) descreve quatro atividades principais do modelo SSM:

- Descobrir sobre a situação problemática, incluindo cultural e política; 
- Formular alguns modelos com atividades definidas relevantes;

- Debater a situação, utilizando o modelo para discutir sobre: a) as mudanças que poderiam melhorar a situação e que são vistas como desejadas e culturalmente implementáveis; b) o ajuste entre interesses conflitantes que propiciarão ações a serem tomadas.

- Agir sobre as circunstâncias para propiciar a melhoria.

\section{A investigação apreciativa e o foco nas potencialidades}

Os defensores da Investigação Apreciativa argumentam que se continuamos procurando problemas, continuaremos encontrando problemas. O modelo criado pelo professor Cooperrider busca nas potencialidades locais a solução para o desenvolvimento e formulação de estratégias (COOPERRIDER e WHITNEY, 1998). A teoria de Cooperrider segue uma linha de abordagem de gestão relativamente nova. Em vez de trabalhar os problemas de uma organização, como faz a maioria dos modelos decisórios, o modelo de Investigação Apreciativa (Appreciative Inquiry) trabalha os fatores positivos de um organismo ou organização.

Apesar de a teoria ser relativamente nova a mitologia grega já relatava a estória de um rei de Chipre, chamado Pigmaleão e discutia sobre a capacidade do ser humano de determinar seus próprios rumos, tornando sonhos em realidades. Segundo a mitologia este rei era um hábil escultor e se apaixonou pela escultura que havia realizado, uma estátua de marfim que esculpira para representar a mulher ideal. Tal era a perfeição da estátua, que Pigmaleão chegou a tratá-la como se fosse real, chamando-a Galatéia. Diz a mitologia que a deusa Afrodite, comovida com os desejos do desesperado escultor, transforma a estátua em uma mulher de carne e osso.

O mito de Pigmaleão inspira atualmente trabalhos em áreas como a psicologia, educação, gestão empresarial e desenvolvimento de sistemas, e está relacionado ao que se chama "efeito Pigmaleão". A teoria relacionada ao efeito Pigmaleão diz que a busca de objetivos positivos pode guiar e induzir as pessoas à auto-superação.

Arante (2002) comenta sobre o efeito Pigmaleão dizendo:

Assim como no caso de outros mitos, Pigmaleão traduz um elemento fascinante do comportamento humano: a capacidade de determinar seus próprios rumos, concretizando planos e previsões particulares ou coletivas. No ambiente de negócios, a definição dos rumos de uma organização, através da elaboração da sua missão e da visão, pode contribuir significativamente para um posicionamento de vanguarda, bem como para geração de valor competitivo.

... embora demande esforço, o efeito pigmaleão nas organizações é possível. Mas isso não será resultado de ação milagrosa de deuses. Os gestores devem procurar potencializar o poder criativo, a inovação, o engajamento e a ação contínua de seus profissionais traduzida em negócios. Querer fugir disso é criar um grande mito, porém sem nenhum significado.

Segundo Sullivan (2004), os estudos sobre "efeito placebo" na área médica, sobre o "efeito Pigmaleão" principalmente na área de educação e sobre a "teoria do desempenho" na área desportiva, sustentam o modelo de Investigação Apreciativa de Cooperrider. 
Por não focar os problemas organizacionais e sim as virtudes, a abordagem apreciativa tem como vantagem sobre outros modelos a facilidade de gerar consenso e a união dos participantes em busca de objetivos comuns, eliminando a atmosfera negativa da busca de problemas, culpados e justificativas. Judy (2005) diz que os princípios que sustentam a Investigação Apreciativa defendem a ideia de que se deve buscar identificar os fatores positivos que contribuem para o sucesso de cada grupo ou organização.

A metodologia de Investigação Apreciativa tem cinco princípios básicos:

- Princípio construcionista: As realidades são construídas sobre as experiências prévias pessoais e organizacionais, que definem o destino da organização (ELOSBRASIL, 2005). Segundo a IISD (2005), as perguntas que geramos no período investigativo definem o ponto para a descoberta de estórias de sucesso, a partir daí um novo futuro pode ser concebido e construído.

- Princípio da simultaneidade: As perguntas e as mudanças acontecem simultaneamente e utilizando-se perguntas apreciativas se favorece a autoestima da outra pessoa (ELOSBRASIL, 2005). Segundo a IISD (2005), as perguntas que fazemos estabelecem o ponto de partida para o que vamos encontrar; e o que descobrimos será a descrição de como o futuro será concebido e construído.

- Princípio poético: As organizações humanas, assim como uma obra de arte, podem ser interpretadas de diversas maneiras e os observadores devem ser vistos como coautores deste trabalho (ELOSBRASIL, 2005). Segundo a IISD (2005), o passado, o presente e o futuro são uma fonte sem fim para o aprendizado, a inspiração e a interpretação, a partir deles podem ser estudadas as derrotas ou os sucessos, a desintegração ou a união, os momentos tristes ou os alegres, os momentos de estresse e derrota ou a criatividade e a inovação.

- Princípio da antecipação: Este princípio defende a ideia de que a visão antecipada do futuro guia o comportamento de cada organismo ou organização em direção a seus sonhos e imaginações e que a imaginação coletiva e o debate a respeito do futuro são os recursos mais importantes que se tem para construir a mudança organizacional (ELOSBRASIL, 2005). Segundo a IISD (2005), as comunidades existem porque os governantes mantêm uma visão compartida do que é a organização, como funciona e como esta deverá ser no futuro.

- Princípio positivo: A abordagem positiva tem o poder de agregar e realimentar as forças e coalizões organizacionais. Segundo ELOSBRASIL (2005), quanto mais positivas são as questões formuladas, mais efetivo é o esforço de mudança. Para a IISD (2005), em muitos temas importantes as pessoas e as comunidades se movem no sentido das questões formuladas. As perguntas sobre os sucessos passados guiam a comunidade em um sentido muito melhor que as perguntas formuladas sobre os problemas e deficiências do sistema. 
A metodologia de Investigação Apreciativa compunha-se originalmente de quatro passos básicos. O Ciclo dos 4 D's originaram dos termos em inglês (Discovery, Dream, Design e Destiny), e refere-se aos passos de Descoberta, Sonho, Planificação e Destino. Posteriormente alguns adeptos desta metodologia incluíram outros passos. O professor Mark Chupp, utiliza um modelo de Investigação Apreciativa (AI) com cinco passos, que chama de 5D's (URBAN UPDATE, 2004). O quinto passo foi adicionado antes do primeiro e vem do termo em inglês "Define", que significa "Definir". Por sua vez, outros autores preferem chamar o último passo de "Delivery" em vez de "Destiny", "Entrega" em vez de "Destino".

\section{A integração dos modelos AI e SSM}

A integração da metodologia Soft Systems Methodology (SSM) à Investigação Apreciativa (AI) busca suprir as dificuldades encontradas na aplicação dos modelos isolados . O Modelo Integrado propõe agregar os princípios básicos que sustentam a Investigação Apreciativa aos princípios advindos do modelo SSM. Esta composição propicia uma visão sistêmica, flexível e construtivista, conduzida pelo estímulo gerado pela investigação positiva.

As características que se deseja absorver da Soft Systems Methodology são: a visão sistêmica, a flexibilidade e o principio construtivista. O modelo de Investigação Apreciativa também apresenta características construtivistas e de flexibilidade, facilitando sua integração ao modelo SSM. Contudo, a principal característica que se deseja absorver do modelo AI é o foco apreciativo positivo. A propriedade apreciativa positiva facilita a geração de consenso e integração dos participantes desde as primeiras etapas do processo de formulação estratégica, facilitando o processo decisório e a implementação das fases subsequentes do modelo.

A idéia de que a verdade é subjetiva e de que não pode ser encontrada por meio do raciocínio lógico e a constatação do caráter não sensível dos números para muitas aplicações, demonstra a necessidade de utilização de um modelo sistêmico-construtivista para apoiar as decisões estratégicas municipais. Este tipo de modelo possibilita a construção do conhecimento e busca entender, de maneira integrada, o sistema que se deseja analisar. Os modelos reducionistas, por outro lado, dividem o problema em pequenas partes, para facilitar seu entendimento, mas desta maneira perdem o senso de totalidade do sistema analisado.

Devido às dificuldades de implementação encontradas nas primeiras etapas do modelo SSM propõe-se a integração dos três passos iniciais do modelo de Investigação Apreciativa, substituindo as duas primeiras etapas do modelo SSM. Também se faz necessário realizar adequações nos demais passos do modelo SSM, possibilitando a integração dos modelos SSM à filosofia da AI.

O foco de resolução de problemas, adotado pela metodologia SSM é abandonado. Desta maneira o Modelo Integrado absorve da AI a característica apreciativa e passa a buscar as 
potencialidades do estado atual (status quo) para transformar este estado em um estado futuro desejado (reflexo do sonho coletivo).

Com este procedimento e pequenos ajustes obtém-se um modelo que segue oito passos (ver Figura 1). Os passos propostos para o Modelo Integrado são:

1. Descobrir - apreciar o que a cidade tem de melhor;

2. Sonhar - criar visões dos resultados esperados para o futuro;

3. Planejar - criar a arquitetura da organização/cidade (construção coletiva de imagens do futuro desejado);

4. Descrever os Subsistemas Relevantes (SR);

5. Representar os Subsistemas Relevantes no Modelo Conceitual (MC);

6. Comparar o Modelo Conceitual (5) com as potencialidades do sistema (1);

7. Debater e propor melhorias possíveis e desejáveis;

8. Implementar as melhorias.

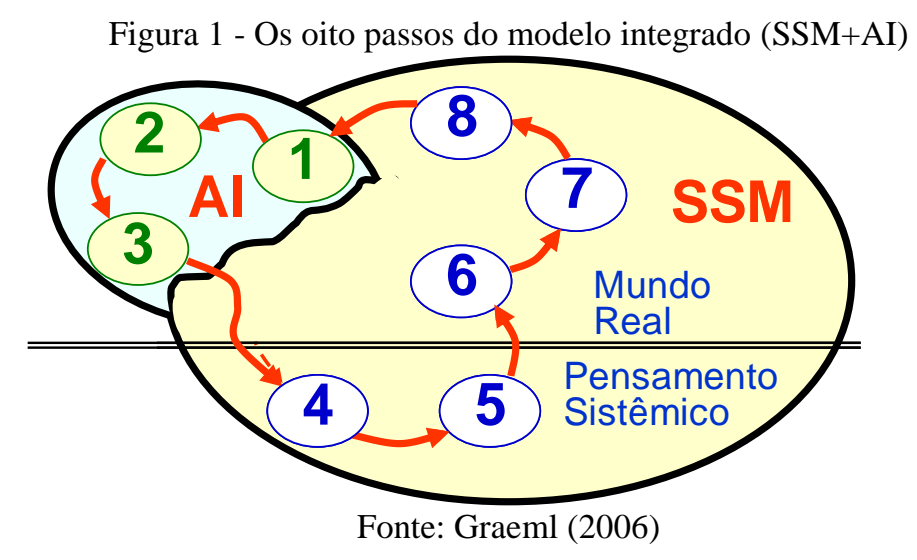

\section{Primeiro passo (descobrir) - aprecia o que a cidade tem de melhor}

Esta etapa é conduzida pelo sentimento de auto-superação pessoal e coletiva, que propicia a criação de um clima que favorece a auto-estima e a descoberta do que se tem de melhor em cada organização ou sistema. O caminho de busca das potencialidades apresenta como vantagem sobre o caminho de "resolução de problemas" o fato de se partir de algo do passado que já se conhece e que apresentou resultados que agradaram às pessoas. Varona (2003) lembra, contudo, que ainda que o enfoque da AI seja o de encontrar os aspectos positivos, também se deve descobrir as formas deficientes de comunicação (injustas ou problemáticas) que apresentam um potencial positivo.

Defendendo a idéia de se tratar os pontos positivos de uma organização Tom White, presidente da GTE Telephone Operations, diz: "A Investigação Apreciativa é uma ciência complexa desenhada para melhorar as coisas. Não podemos ignorar os problemas, somente necessitamos enfocá-los pelo outro lado." (COOPERRIDER e WHITNEY, 1998, p.7). Cooperrider e Whitney dizem que "o outro lado" mencionado por Tom White, significa o centro da mudança positiva.

Uma forma prática de aplicação desta etapa do modelo é dividir os participantes do processo 
de construção do conhecimento e apoio à decisão, em grupos de no máximo 8 pessoas, facilitando a discussão e a participação de todos os envolvidos. Dentro destes grupos formam-se pares, preferentemente com pessoas que se conhecem pouco ou não se conhecem, propiciando um clima de investigação e descoberta, buscando-se gerar empatia e confiança entre os participantes. Solicitase que o companheiro descreva as 3 experiências pessoais, em favor social ou de outra pessoa, para as quais sua participação foi fundamental e que lhe deram entusiasmo, felicidade, satisfação e orgulho. A limitação de 3 experiências possibilita a descoberta e explicitação dos tópicos mais importantes e relevantes para cada individuo. Segue-se uma autocrítica positiva que revela as potencialidades pessoais ainda pouco exploradas. Solicita-se que o entrevistado faça uma autoreflexão e uma descrição sobre o que diria sobre si uma pessoa que conhecesse todo o seu potencial e talento se lhes pedisse que descrevesse suas três melhores qualidades (capacidades e competências).

Após cada participante ser entrevistado por seu companheiro, passa-se a discussão entre os membros de cada grupo. Nesta discussão cada pessoa relata aos demais os momentos de maior satisfação e orgulho descritos por seu companheiro e as três maiores qualidades que alguém que lhe conhecesse descreveria sobre si.

Depois de propiciado um clima positivo de confidência e cooperação entre os participantes e de revelados os valores e potencialidades individuais, busca-se identificar as potencialidades do sistema, neste caso as potencialidades de cada cidade. Conhecendo-se os valores individuais e do grupo fica mais fácil apreciar de maneira coletiva e cooperativa as potencialidades do sistema.

Cada grupo deve discutir os fatos positivos que ocorreram em sua cidade, região, país ou no mundo e que influenciaram positivamente o bem estar da população de sua cidade. A partir disto o facilitador deve propor que cada grupo apresente os três fatores ou características mais importantes de sua cidade, sendo que cada aspecto deve ser resumido e expresso por uma única palavra.

Posteriormente, cada grupo apresenta aos demais participantes as três características positivas sobre sua cidade, destacadas pelo grupo.

\section{Segundo passo (sonhar) - cria visões dos resultados esperados para o futuro}

Os sonhos coletivos sofrem grande influência dos relatos, experiências e valores pessoais e coletivos, descritos na etapa de descoberta. A etapa dos sonhos busca estimular o envolvimento dos participantes e a geração de imagens coletivas sobre o futuro desejado. $\mathrm{O}$ facilitador ou condutor do processo deve solicitar aos participantes que tentem projetar em suas mentes um futuro esperado não muito distante para a população de sua cidade, de seu país e do mundo.

Se a fase do "sonho" for realizada em um dia diferente do exercício realizado na fase da "descoberta" deve-se revisar as histórias de sucesso e as potencialidades mencionadas na etapa anterior, antes de se passar para a etapa do "sonho". Isto ajuda a assegurar que o "sonho" está unido 
aos logros do passado e conectado a experiências de sucesso reais (ASHFORD e PATKAR, 2001). As apresentações realizadas em cartolinas ou "flip charts" facilitam a revisão do processo e auxiliam na geração de novas idéias e "sonhos" a partir das experiências relembradas por outros participantes.

Uma maneira de estimular a fase do sonho, mencionada por BAWB Brasil (2005), é solicitar que os participantes imaginem que foram dormir e que quando acordaram haviam passado 10 anos. O sonho deve expressar a maneira como cada um gostaria de ver o futuro tornar-se realidade, beneficiando a si próprio, aos seus vizinhos e a toda sociedade. Dado um tempo para que os grupos formulem os sonhos, o facilitador solicita que cada grupo selecione as três palavras que melhor representem os objetivos que poderia transformar os seus sonhos em realidade. Após esta etapa os grupos apresentam aos demais as palavras escolhidas e o facilitador as transcreve em um único quadro de forma que sejam visíveis a todos os participantes do processo. Ao final, por votação, são escolhidos os "sonhos" que devem ser levados adiante.

\section{Terceiro passo (planejar) - cria a arquitetura da organização}

Esta etapa visa construir imagens positivas do futuro, transformando os "sonhos" em objetivos e explicitando de maneira provocativa o que os grupos gostariam de manter e melhorar no sistema.

Esta etapa inicia avaliando os sonhos mais votados na etapa anterior, levando em conta as dificuldades e prazos para atingir cada objetivo. Segundo Ashford e Patkar (2001, p.27), para a construção coletiva de imagens positivas do futuro o facilitador deve estimular os participantes do processo a realizar o planejamento em três distintos níveis:

- Desdobramento do "sonho" em objetivos e planos de ação de curto prazo;

- Discussão de estratégias de longo prazo para atingir objetivos mais desafiantes;

- Avaliação das mudanças estruturais que podem reforçar as potencialidades, valores centrais e o sentido de vida da organização, e criação de mecanismos que possibilitem o aprendizado organizacional contínuo.

\section{Quarto passo (descrever) - descreve os subsistemas relevantes (SR)}

Esta etapa visa descrever os subsistemas relevantes para o processo de transformação. $\mathrm{O}$ conceito de Definição Fundamental (Root Definition) foi absorvido da Soft Systems Methodology e ajuda a construir um modelo teórico que contenha os fatores relevantes para a consecução dos objetivos estabelecidos.

Na metodologia SSM esta etapa era facilitada pela utilização do mnemônico CATWOE, que representa os clientes $(\mathrm{C})$, os atores $(\mathrm{A})$, o processo de transformação $(\mathrm{T})$, a visão do mundo $(\mathrm{W}), \mathrm{o}$ dono do problema ou proprietário $(\mathrm{O})$ e as restrições ambientais $(\mathrm{E})$. O Modelo Integrado proposto utiliza uma idéia similar a da SSM, mas estruturada sobre conceitos distintos. 
Seguindo a filosofia do Modelo Integrado proposto, em vez de identificar as "restrições ambientais" (E), como faz a SSM, busca-se identificar as potencialidades (P) do sistema. As potencialidades servem como ponto de partida para estabelecer os objetivos e identificar o processo de transformação necessário para atingi-los.

Outro elemento identificado na definição fundamental da SSM e dispensável no modelo proposto é o "dono do problema" (O), aquele ou aqueles que podem interromper o processo quando acharem conveniente. A metodologia integrada não busca identificar as barreiras e obstáculos a serem vencidos e sim os caminhos que podem facilitar a consecução dos objetivos. Desta maneira, considera-se mais importante identificar possíveis parceiros (P) que auxiliem ou facilitem o transcorrer do processo.

O conceito de "visão do mundo" ou "ponto de vista" (W) utilizado pela SSM é similar ao utilizado pela AI. A SSM descreve o ponto de vista ou pressuposto que orienta o processo de transformação, enquanto que a AI desafia os participantes do processo a atingirem os objetivos por eles definidos, através de proposições provocativas. O Modelo Integrado absorve da AI o conceito de proposição provocativa $(\mathrm{P})$ e utiliza estas proposições como ferramenta de estímulo e desafio para consecução dos objetivos traçados.

\section{Quinto passo (representar) - representa o modelo conceitual (MC)}

O quinto passo do Modelo Integrado corresponde ao quarto da SSM. Esta etapa utiliza a Definição Fundamental para construir e representar o Modelo Conceitual (Figura 2). O Modelo Conceitual descreve as atividades teoricamente essenciais para o funcionamento do Pensamento Sistêmico, possibilitando atingir o objetivo estabelecido através da transformação planejada.

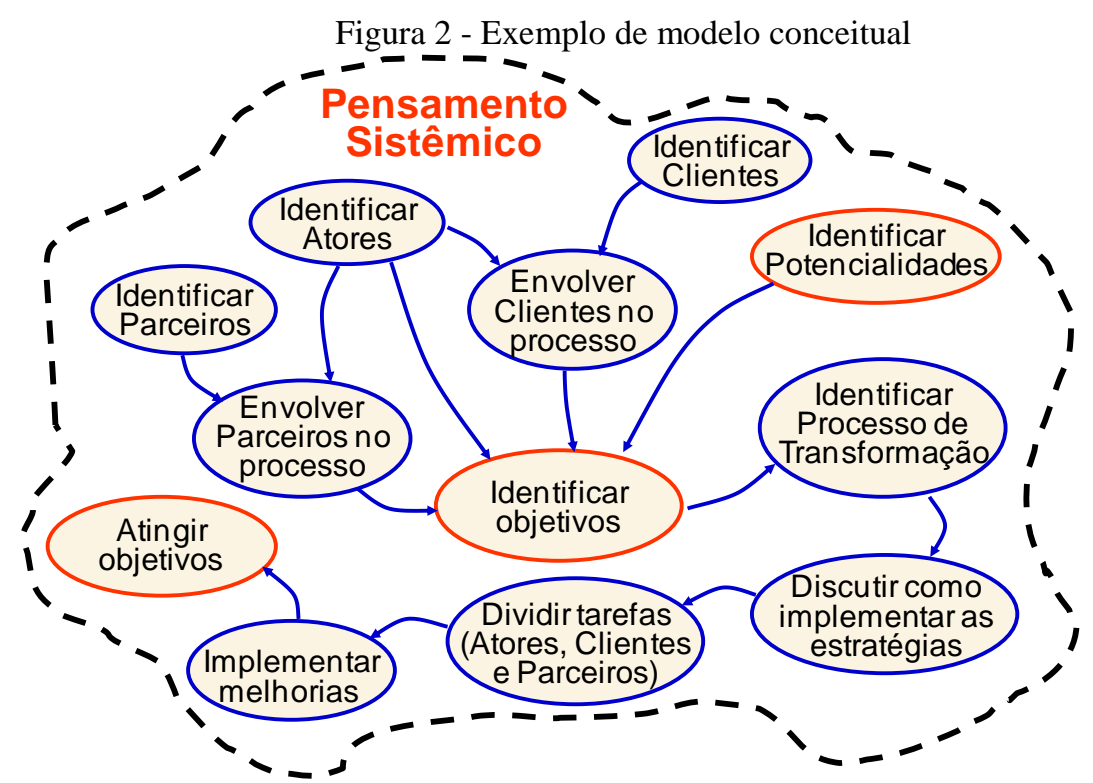

Fonte: Graeml (2006) 
$\mathrm{Na}$ representação gráfica da Figura 2 podem ser identificados possíveis parceiros para o processo de melhoria. Esta é uma recomendação da teoria "Change Management Iceberg" de Wilfried Krüger (apud 12MANAGE.COM, 2005). Krüger faz uma analogia de um iceberg com a área gerencial, dizendo que a maior parte do iceberg não se vê por estar debaixo da água. Dentre outros fatores submersos, Krüger cita os oponentes, possíveis oponentes, os parceiros e os possíveis parceiros. O Modelo Integrado proposto segue, neste caso, a filosofia da Investigação Apreciativa, buscando identificar apenas as potencialidades do sistema e não possíveis restrições.

\section{Sexto passo (comparar) - compara o modelo conceitual com o sistema real}

O sexto passo do Modelo Integrado compara o Pensamento Sistêmico representado no Modelo Conceitual ( $5^{\circ}$ passo) com as potencialidades encontradas no Sistema Real ( $1^{\circ}$ passo). Esta etapa diferencia-se da etapa aplicada na SSM, pois nesta metodologia compara-se o Pensamento Sistêmico com a Situação Problemática.

O Modelo Integrado proposto utiliza as potencialidades do Sistema Real para alimentar o Pensamento Sistêmico (Figura 3). O "sonho", traduzido em objetivos, faz parte do Sistema Real e serve como guia tanto para o processo de transformação como para o monitoramento e controle do desempenho das ações e objetivos. Esta interação do Sistema Real com o Pensamento Sistêmico, descrito no Modelo Conceitual, possibilita a análise de viabilidade de implementação do modelo e a detecção de possíveis inconsistências. Checkland e Scholes (1990, p.44) dizem que o objetivo da comparação do modelo sistêmico com o modelo real é apenas para "encontrar um estado de acomodação entre os diferentes interesses dentro da situação" e não para refinar e melhorar o modelo. As diferenças encontradas na comparação do Modelo Conceitual com as potencialidades do Sistema Real podem ser utilizadas como base para discussão na etapa seguinte, sobre:

- A relevância dos sistemas;

- O funcionamento dos sistemas (como são e como deveriam ser);

- As implicações da implementação do Modelo Conceitual.

\section{Sétimo passo (debater) - debate e propõe melhorias possíveis e desejáveis}

O sétimo paso do Modelo Integrado prevê a discussão sobre as diferenças encontradas entre o Sistema Real e o Modelo Conceitual. Esta discussão pode gerar idéias que possibilitem a correção do plano traçado, garantindo o desenvolvimento e a sustentabilidade da estratégia. O Modelo Integrado parte das potencialidades do sistema e de coisas que já funcionaram e agradam à população, desta maneira é mais fácil atingir resultados efetivos do que utilizando modelos que partem de problemas e de situações de conflito. Esta etapa pode ser realizada novamente em grupo, facilitando a coordenação das propostas. Cada grupo deve discutir e, quando muito, propor uma melhoria. A restrição em uma única melhoria evita que se inicie a busca por problemas e por encontrar e descrever sistemas "perfeitos". As melhorias mais votadas podem ser implementadas e 
as demais sugestões podem ser reflexionadas em outras etapas do ciclo do modelo (no processo cíclico de retroalimentação do modelo). Isto proporciona aos participantes a sensação de entusiasmo em continuar debatendo e promovendo melhorias no sistema, pois sempre haverá algo para melhorar.

Figura 3 - Exemplo de modelo conceitual interagindo com o sistema real

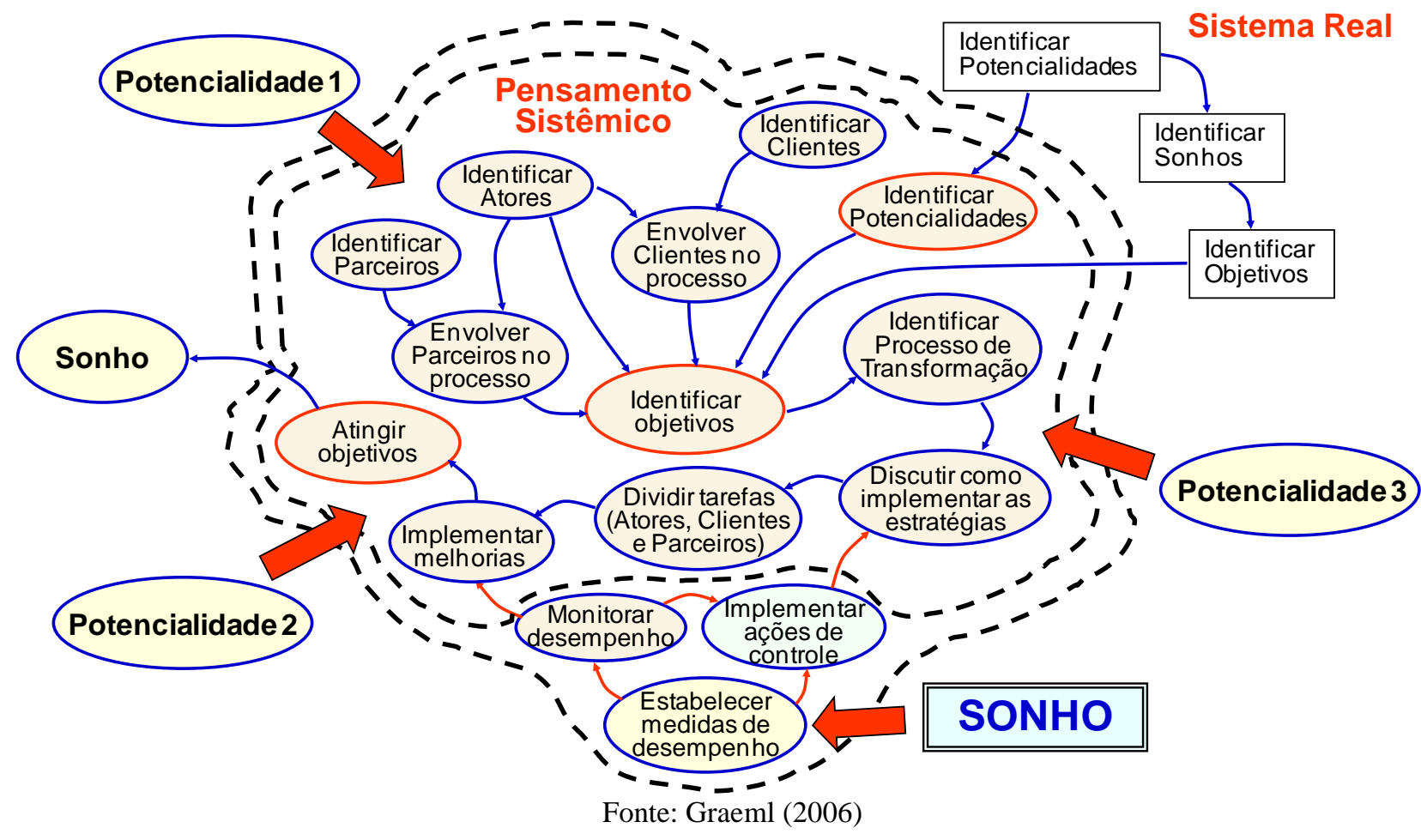

\section{Oitavo passo (implementar) - implementa as melhorias}

O oitavo passo do Modelo Integrado prevê a implementação das estratégias e ações estabelecidas. Os passos anteriores geraram o conhecimento sobre o problema e o sistema como um todo, facilitando a implementação dos planos e estratégias. O Modelo Integrado segue a linha de continuidade proposta tanto pela metodologia SSM como pela AI.

\section{O processo cíclico - retroalimenta o modelo}

O processo cíclico poderia ser considerado como um nono passo do Modelo Integrado, um passo de retroalimentação do processo de implementação do modelo. Considera-se o processo de aprendizado como sendo um processo contínuo e cíclico, cujo resultado esperado é o aprendizado gerado pela discussão, debate e argumentação. Depois de implementadas as melhorias e finalizado o primeiro ciclo do Modelo Integrado este processo pode ser novamente reiniciado. O novo ciclo deve revelar novas potencialidades do sistema e o último passo do processo deve deixar uma sensação de satisfação pelos resultados obtidos e de motivação e desafio pelo que ainda necessita ser realizado. 


\section{Conclusões}

$\mathrm{O}$ arquétipo proposto neste trabalho propicia um modelo teórico-metodológico que auxilie na elaboração de estratégias efetivas, dedicadas às necessidades e potencialidades de cada município. Como resultado desta integração obtém-se um modelo de apoio à decisão com característica sistêmica, apreciativa, construtivista e flexível.

A flexibilidade, absorvida do modelo SSM, possibilita um melhor foco dos problemas urbanos locais e a proposição de alternativas estratégicas dedicadas à realidade de cada cidade. A flexibilidade garante ao modelo de decisão o acompanhamento das variações externas ao sistema, desta maneira o modelo de gestão não é forçado a atuar de maneira corretiva.

A visão holística do modelo demonstra ser de grande importância para a elaboração de um bom planejamento estratégico, possibilitando uma gestão urbana prospectora e sustentável. A característica construtivista possibilita a construção do conhecimento sobre a realidade local e descoberta das potencialidades e problemas de cada sistema. Silva e Menezes (2001) lembram que a realidade não é única e que existem tantas quantas forem as suas interpretações e comunicações.

A característica apreciativa, derivada do modelo de Investigação Apreciativa, facilita o consenso e a união dos participantes do processo. Esta característica foi considerada, no decorrer do estudo, fundamental para a efetiva viabilidade do modelo decisório proposto. $\mathrm{O}$ acompanhamento de dois casos reais, de problemas de conflitos entre políticos e entre políticos e população, evidenciaram a necessidade de um modelo que atendesse as seguintes características:

- Facilitasse a formulação de estratégias dedicadas às potencialidades e características de cada cidade;

- Aumentasse a capacidade dos prefeitos para tomar decisões estratégicas sustentáveis;

- Possibilitasse a aproximação do político à população local;

- Facilitasse a negociação, o consenso e a criação de sonhos coletivos;

- Estimulasse a participação da população no processo de estabelecimento de objetivos, formulação estratégias e implementação e conservação de obras públicas;

- Estabelecesse mecanismos de implementação e controle do processo de transformação;

- Diminuísse a complexidade e a dificuldade da tomada de decisão em situações complexas, confusas e desordenadas.

Para atingir os objetivos estabelecidos o modelo proposto apresenta etapas simples e bem definidas, descrevendo passo a passo uma possivel maneira de se conduzir o planejamento e o desenvolvimento estratégico de uma cidade de forma participativa e colaborativa, reduzindo a complexidade de todas as etapas do plano estratégico (da negociação e formulação à implementação). Desta maneira se possibilita a formulaçao de estrategias dedicadas a las 
potencialidades e necessidades locais enfocando a melhoria da qualidade de vida da população e a sustentabilidade da própria estratégia.

\begin{abstract}
The current political-administrative Brazilian scenario makes more and more evident the need for dedicated strategic solutions to local problems of each city, state or area. This problem also seems to occur in countries with different democratic systems, occurring also in first world countries. The democratic system itself provides -as one would expect- the participation of individuals and coalitions with different views and interests. This article presents part of the study of the doctoral thesis of one of the authors and describes the archetype of a model that integrates Appreciative Inquiry Methodology to the Soft Systems Methodology. The integration of these methodologies results in a theoretical and methodological framework that can support the development of sustainable and effective strategies, which increases the possibility of negotiation between different parts and that can be dedicated to particular needs and potentialities of each municipality. As a result of this integration it was developed a decision support model that facilitates consensus and unify forces in pursuit of common goals, allowing a better quality of life of local people.
\end{abstract}

Key-words: appreciative inquiry, soft systems methodology, urban strategic planning, consensus decision-making, decision aid model.

\title{
Referências
}

12MANAGE.COM. Change phases - Kotter, 2006. Disponível em:

http://www.12manage.com/methods_kotter_change.html. Acesso em: 11 de novembro/2005.

ARANTE, A. O "efeito Pigmaleão" nas organizações. Recife: Desafio 21 - gestão e competitividade, 2002. Disponível em: http://www.redegestao.com.br/desafio21/gec179.html. Acesso em: 20 de março/2005.

ASHFORD, G.; PATKAR, S. The positive path: using Appreciative Inquiry in rural indian communities: International Institute for Sustainable Development (IISD), 2001. Disponível em:

http://www.iisd.org/pdf/2001/ai_the_positive_path.pdf. Acesso em: 5 de abril/2005.

BAWB BRASIL. $3^{\text {a }}$ Conferência internacional BAWB: empresas que lucram e beneficiam o mundo. Curitiba, 2005. Disponível em: http://www.bawb.org.br/bawb2005/entrevista\%20bawb\%202005.pdf. Acesso em: 15 de outubro/2005.

BUNCH, M. J. An Adaptive Ecosystem Approach to Rehabilitation and Management of the Cooum River Environmental System in Chennai - India. 2000. Doctor of Philosophy - University of Waterloo, Waterloo - Canada, 2000 .

CHECKLAND, P. Systems thinking, systems practice. Chichester [Sussex] ; New York: J. Wiley, 1981. xiv, 330 p. p. . Soft Systems Methodology: a 30-year retrospective. Chichester: John Wiley \& Sons, 1999.

CHECKLAND, P.; SCHOLES, J. Soft Systems Methodology in action. England: Wiley, 1990. xv, 329 p. p.

COOPERRIDER, D. L.; WHITNEY, D. A positive revolution in change: Appreciative Inquiry: Case Western Reserve University, 1998. Disponível em: http://appreciativeinquiry.cwru.edu/uploads/whatisai.pdf.

ELOSBRASIL. Inspiroteca - Investigação Apreciativa, 2005. Disponível em:

http://www.elosbrasil.org.br/br/paginas.asp?id_site=br\&cod_pagina=2. Acesso em: 5 de abril/2005.

GRAEML, F. R. A Construção de um Arquétipo que Integra a Investigação Apreciativa à Soft Systems Methodology Possibilitando a Gestão Estratégica Sustentável de Cidades. 2006. 232 f. Tese (Doutorado em Engenharia de Produção) - Programa de Pós-Graduação em Engenharia de Produção, Universidade Federal de Santa Catarina, Florianópolis. 
IISD. From problems to strengths: International Institute for Sustainable Development (IISD), 2005. Disponível em: http://www.iisd.org/ai/default.htm. Acesso em: 5 de abril/2005.

JUDY, S. An introduction to Appreciative Inquiry, 2005. Disponível em:

http://www.silvafor.org/publications/library/docs/AI_Intro.pdf. Acesso em: 13 de abril/2005.

SILVA, E. L. D.; MENEZES, E. M. Metodologia da pesquisa e elaboração de dissertação. Florianópolis, 2001.121 p.

SULLIVAN, M. The promise of appreciative inquiry in library organizations. Library Trends, v. 53, n. 1, p. 218230, Summer, 2004.

URBAN UPDATE. Appreciative Inquiry in an urban context: an interview with Dr. Mark Chupp: Cleaveland State University, 2004. Disponível em: http://urban.csuohio.edu/news/urbanupdate/uu_nov_dec04.pdf. Acesso em: 6 de abril/2005.

VARONA, F. Todavía es posible soñar: teoría apreciativa y comunicación empresarial. San José - CA. USA: San José State University, 2003. Disponível em: http://appreciativeinquiry.case.edu/uploads/TACOR\%2020033.pdf. Acesso em: 14 de março/2005.

\section{Dado dos autores}

Nome completo: Felipe Reis Graeml

Filiação institucional: Universidad Europea de Madrid (UEM)

Departamento: Direção de Empresa

Função ou cargo ocupado: Professor Associado

Endereço completo para correspondência (bairro, cidade, estado, país e CEP): C/ Tajo s/n. Campus Universitário - Villaviciosa de Odón. Madrid - ESPANHA - CEP: 28670

Telefones para contato: 0034912115659

e-mail: felipe.reis@uem.es

Nome completo: Rolf Hermann Erdmann

Filiação institucional: Universidade Federal de Santa Catarina (UFSC)

Departamento: Administração

Função ou cargo ocupado: Professor

Endereço completo para correspondência (bairro, cidade, estado, país e CEP): Centro Socioeconômico - Campus Universitário - Trindade - Florianópolis - Santa Catarina - Brasil - CEP: 88040-900

Telefones para contato: 0055 (48) 37217082

e-mail: erdmann@cse.ufsc.br

\section{Submetido em:}

Aceito em: 